\title{
The intergenerational transmission of human capital: the role of skills and health
}

\author{
Petter Lundborg ${ }^{1} \cdot$ Martin Nordin $^{1}$. \\ Dan Olof Rooth ${ }^{2}$
}

Received: 24 January 2017 / Accepted: 18 April 2018 / Published online: 22 May 2018 (C) The Author(s) 2018

\begin{abstract}
We provide new evidence on some of the mechanisms reflected in the intergenerational transmission of human capital. Applying both an adoption and a twin design to rich data from the Swedish military enlistment, we show that greater parental education increases sons' cognitive and non-cognitive skills, as well as their health. The estimates are in many cases similar across research designs and suggest that a substantial part of the effect of parental education on their young adult children's human capital works through improving their skills and health.
\end{abstract}

Keywords Intergenerational transmission - Human capital · Education · Health · Cognitive skills $\cdot$ Non-cognitive skills $\cdot$ Adoptees $\cdot$ Twins

JEL Classification $\mathrm{I} 12 \cdot \mathrm{I} 11 \cdot \mathrm{J} 14 \cdot \mathrm{J} 12 \cdot \mathrm{C} 41$

\section{Introduction}

How much does the adult success of children depend on their family background? This question is of long-standing interest in the social sciences partly because the answer reveals something about the degree to which inequality is transmitted across generations. An extensive literature has tackled the question by providing estimates

\footnotetext{
Responsible editor: Erdal Tekin

Petter Lundborg

petter.lundborg@nek.lu.se

1 Department of Economics, Lund University, P.O. Box 7082, SE-220 07 Lund, Sweden

2 Swedish Institute for Social Research, Stockholm University, Stockholm, SE-106 91, Sweden
} 
of the relationship between parental education and children's education. ${ }^{1}$ Such estimates reflect both the influence of 'nature' and 'nurture' but a recent literature, mostly based on a twin and an adoption design, has established that a substantial part of the transmission of education across generations reflects a causal effect of parental education (e.g. Behrman and Rosenzweig 2002; Sacerdote 2002; Plug and Vijverberg 2003; Plug 2004; Björklund et al. 2006; Holmlund et al. 2011; Amin et al. 2015). ${ }^{2}$

While this literature has enhanced our understanding of the intergenerational transmission of human capital, we still have limited knowledge about what it is that well-educated parents bring to their children. ${ }^{3}$ In other words, what are the particular mechanisms that are involved in the intergenerational transmission of human capital? Do the estimates reflect, for instance, that mothers' and fathers' education improves the health of their children, who, in turn, go on to obtain more schooling? A growing literature points to the importance of early health capital for education and earnings (see Currie 2009 and Almond and Currie 2011). Or do the estimates reflect that more educated parents get smarter children or children with greater social skills? Studies by Heckman and others emphasise the importance of skill acquisition early in life for later life outcomes (Heckman et al. 2006). Other mechanisms may be at work as well, where education is transmitted through information or through having access to networks. While a small and mostly instrumental variable-based literature has provided some evidence on potential mechanisms, much remains to be learned (see e.g. Currie and Moretti 2003; McCrary and Royer 2011; Carneiro et al. 2013; Piopiunik 2014; Lundborg et al. 2014b, and the literature review below.)

In this paper, we add to the literature on the mechanisms behind the transmission of education across generations by exploiting rich administrative data from the Swedish military enlistment records, where cognitive skills, non-cognitive skills, and health have been measured for almost the entire population of 18-year-old Swedish males. To these data, we have merged register-based information on parental education, including information on parents who are twins and parents who have adopted a child.

Our analysis contributes to the existing literature in mainly two ways. Firstly, we contribute to the literature on the determinants of children's skills and health. While there is growing evidence for the importance of skills and health during childhood and adolescence, we know less about their determinants. Moreover, besides schooling, there is little evidence on the effect of parental education on other important outcomes of their adolescent children.

Secondly, we contribute to the literature on the intergenerational transmission of human capital by providing new evidence on some of the mechanisms. With our data, we are able to open the black box of possible mechanisms and examine the role of skills and health in the transmission of human capital. If parental

\footnotetext{
${ }^{1}$ The particular interest in education reflects the common belief that the education of one's parents is a major determinant of one's success in life (Haveman and Wolfe 1995).

${ }^{2}$ See Black and Devereux (2010), Björklund et al. (2010a), Holmlund et al. (2011), and Sacerdote (2011) for recent overviews on the literature on intergenerational mobility.

${ }^{3}$ We review the literature on the effect of parental schooling on specific child outcomes in Section 2 below.
} 
schooling is found to affect their children's skills and health, this may also provide some clues to how the intergenerational transmission of education arises. Moreover, this would suggest that poor health and poor skills during childhood and adolescence are important mechanisms for the intergenerational transmission of human capital and economic status. Since we are able to use both an adoption and a twin design, we are thus able to directly address the possible mechanisms reflected in the previous twins and adoption-based literature on the transmission of education across generations.

Improving the understanding of the underlying mechanisms is important for many reasons. ${ }^{4}$ As argued by Currie (2009), it is only by opening the black box of the family that we can understand why it is that better backgrounds promote success in life. But improved knowledge about the mechanisms could also be useful information for policy makers. For instance, policies that increase the level of education in society could be considered as more valuable if they also improve the education of people's offspring through increasing the offspring's skills and the health, rather than only through improving their study results in a narrower sense or through a pure informational advantage. The reason is that improved skills and health may have benefits that stretches way beyond increased educational attainment. For instance, improved skills have been linked to reduced crime and risky behaviour, in addition to higher education and earnings (Heckman et al. 2006; Lundborg et al. 2016).

Our results favour the view that skills and health during childhood and adolescence are important mechanisms through which the intergenerational transmission of education arises. We show that parental education increases sons' cognitive and noncognitive skills, as well as their health. Moreover, across a number of outcomes, the estimates are rather similar using both the adoption and twin design, especially when we restrict the adoption data to children adopted within their first year of life. In addition, we obtain some pronounced gender differences, where the education of the father matters more for the formation of cognitive and non-cognitive skills, whereas the mother's education matters more for the son's health. Such patterns may reflect differences in the effectiveness of investments in children across genders and areas and/or role model effects.

We believe that our estimates appear reasonable, given the results obtained in previous studies on the intergenerational transmission of human capital and on the schooling returns to skills. Taking the example of cognitive skills, we show that the effect of parental education on such child skills could explain half of the causal effect of parental schooling on children's schooling obtained in previous studies. Given the positive effects that parental schooling has on non-cognitive skills and health outcomes, this suggests that a major part of the transmission of education across generations runs through improved capacities of children.

\footnotetext{
${ }^{4}$ The importance of understanding the mechanisms is also argued in a recent overview by Black and Devereux (2010), where the authors write: 'The focus of current research is on establishing a link between parent and child education; understanding the underlying mechanisms is a clear direction for future research'. A similar view is expressed by Holmlund et al. (2011), who conclude that 'From our perspective, the roadmap for future research lies in a better understanding of the mechanisms that explain how parental schooling is passed on to the next generation'.
} 
This paper is organized as follows. The next section reviews some of the relevant literature on the intergenerational transmission of human capital. Section 3 describes the data used in this study. Section 4 describes and discusses the two empirical strategies used in this paper: the adoption design and the twin design. Section 5 presents the results and Section 6 summarises our findings and draws some conclusions.

\section{Related literature}

In the following section, we review some of the key studies in the literature that estimates the effect of parental education on child outcomes. We start with the adoptionand twins-based literature and then move on to the instrumental variable-based literature.

Most studies have identified positive and significant nurturing effects of parental schooling on children's schooling, although the magnitude varies across studies and across contexts. In early adoption studies, such as Dearden et al. (1997), Sacerdote (2000, 2002), and Plug (2004), relatively large nurturing effects were obtained in the USA and the UK. Later adoption studies usually obtain smaller 'nurturing' effects. For the USA, Sacerdote (2007) used data on Korean adoptees who were randomly assigned to families, where the smaller effect perhaps reflects that there was less parent-child matching taking place. Smaller effects, although significant, were also reported in the novel study by Björklund et al. (2006), where data on both the biological and adoptive parents of adopted children were used. Similar estimates were obtained in a recent paper by Holmlund et al. (2011), using data on both internationally adopted children and children adopted within Sweden.

The twin-based literature reports mixed findings regarding the influence of parental schooling. Evidence on the role of maternal education was obtained in a paper by Amin et al. (2015), where only the mother's education mattered in a sample of MZ twins. Bingley et al. (2009), using data on Danish MZ twins, showed that the importance of the maternal education became greater in more recent cohorts. Contrasting evidence was obtained in Hægeland et al. (2010), who used both an adoption and a twin design. They found that mothers' education mattered more for the child's exam scores at age 16 than father's education in the adoption design but found no effects of parental education when using a twin design. Moreover, using data on monozygotic twin parents, Behrman and Rosenzweig (2002) found no effects of mothers' schooling on children's schooling. Similar results were obtained in Holmlund et al. (2011) and Pronzato (2010), using samples of pooled MZ and DZ twins in Sweden and Norway, respectively.

Besides the adoption and twin studies, a small literature uses an IV design to study the intergenerational transmission of schooling. Black et al. (2005) used a reform of the Norwegian schooling system as an instrument for parental schooling and found no causal relationship between the father's education and the child's education level. For mothers, they report a small effect on the son's education (but not on the daughter's). Similar IV results were obtained by Holmlund et al. (2011), where the mother's 
education was found to be slightly more important. ${ }^{5}$ De Haan (2011) used a nonparametric bounds analysis and found that increasing mother's and father's schooling to a college degree had a positive effect on child's schooling.

Most of the studies cited above have established that there exists a 'nurturing' effect of parental education on children's education, although often small in size. But what are the mechanisms behind this effect? To shed light on potential mechanisms, it would be informative to consider the relation between parental education and intermediate child outcomes, such as skills and health. In the adoption literature, one of the few studies doing so is Sacerdote (2000), who shows significant nurturing effects of parental years of schooling on children's cognitive test scores in a small sample of Korean adoptees in the USA. No significant nurturing effects were found in Sacerdote (2007), however, where the relation between mothers' education and children's BMI and drinking behaviour was estimated. In a recent Swedish paper, Lindahl et al. (2016) use data on Swedish-born adopted children, where data on both biological and adoptive parents is available. Relating child health outcomes to the education of both types of parents, they find a positive and significant relationship between the adopting parent's schooling and child health but no significant influence of biological parent's schooling.

In the twin-based literature, the only study on potential mechanisms that we are aware of is a working paper by Bingley et al. (2009). They use Danish data and estimate the effect of parental schooling on the birth weight of the offspring. The results show that the mother's schooling increases the birth weight of their offspring but that the father's schooling has no effect.

Most of the evidence on the effect of parental education on child outcomes instead comes from instrumental variable studies. ${ }^{6}$ The first IV study on the topic was Currie and Moretti (2003), who used the expansion in the number of colleges across U.S. states as an instrument for mothers' schooling. They found that the increase in college attendance of women improved their children's health, in terms of birth weight and gestational age, and led to less smoking among mothers.

In a study using UK data, Lindeboom et al. (2009) exploited a compulsory schooling reform to estimate the causal effect of schooling on child health. They found no evidence of a causal effect of parental schooling on child health outcomes at birth and at ages 7, 11, and 16. Chevalier and O'Sullivan (2007), however, found that the

\footnotetext{
${ }^{5}$ A number of additional studies have used an IV strategy to study the effect of parental education on various educational outcomes of children, such as grades, grade repetition, and post-compulsory school attendance (Chevalier 2004; Oreopoulos et al. 2006; Maurin and McNally 2008; Carneiro et al. 2013). These studies find a positive effect of education, the exception being Chevalier, where a negative effect on the likelihood of the child having post-compulsory schooling was obtained for fathers' education.

${ }^{6}$ Note, however, that the results from this literature may be hard to generalise to the twin and adoption literature, since the IV estimates reflect local average treatment effects, where the instruments used normally affect people at the lower end of the educational distribution, while results using adopted children effectively exploit variations in education in a group of well-educated parents. The twin design exploits differences in education between twin parents, where the differences are often found to be quite evenly distributed across the distribution of education. Any differences in results from studies using the twin and adoption design could thus also reflect that different sources of variation in the data are used.
} 
reform had heterogeneous effects and that the most impacted groups experienced larger changes in infant birth weight. Piopiunik (2014) show that education can affect attitudes towards schooling and find that parents with more schooling value good school performance by their children more highly and are also more likely to believe that it is important for children to be studious.

Carneiro et al. (2013) used U.S. data and instrumented mothers' education with the presence of colleges at age 17 in the state of residence and with local labour market conditions. They found a strong effect of maternal education on child cognitive outcomes, but also on measures of behaviour problems. McCrary and Royer (2011) combined data on exact birth dates and age-at-school entry policies in the spirit of Angrist and Kreuger's quarter of birth instrument. Using data on all births in California during the years 1989-2002, and using birth date as an instrument for schooling, they find no evidence of a causal effect of maternal schooling on infant health outcomes.

A closely related IV paper is Lundborg et al. (2014b) who use exposure to the Swedish compulsory schooling reform in the $50 \mathrm{~s}$ as an instrument for schooling. Using the same data sources as in this paper, the results suggest that mothers' schooling positively affects cognitive skills, non-cognitive skills, and health of their sons. They found no effect of fathers' schooling, however. ${ }^{7}$

The literature review above suggests that there is rather mixed evidence regarding the causal effect of parental schooling on child outcomes such as health and cognitive skills in developed countries. In a comprehensive survey on the literature on children's health and parental socioeconomic status, Currie (2009) concludes that it is still difficult to prove that the relationship between parental background and children's health is a causal relationship and that more research is needed. ${ }^{8}$

\section{Data}

For the purpose of this study, we merged a number of different registers. This includes the Register of the Total Population, the Multi Generation Register, the Swedish Military Enlistment Register, the Swedish Register of Education, the National Tax Records, and the Swedish Twin Registry.

\footnotetext{
${ }^{7}$ Hjalmarsson et al. (2015) used the same reform to study the effect of parental education on children's crime, finding that parents' schooling reduced crime.

${ }^{8}$ There are also a number of studies that estimate the relationship between various outcomes across generations where the results may point to potentially important mechanisms for the intergenerational transmission of education. These include, for instance, Black et al. (2009), Anger and Heineck (2010), Grönqvist et al. (2016), and Björklund et al. (2010b), who all study the transmission of IQ across generations, and Lindqvist and Hjalmarsson (2010, 2012, 2013) who study the intergenerational transmission of crime. Moreover, Amin et al. (2011), studies the intergenerational transmission of income, using a twin design. Corak and Piraino (2011) study the intergenerational transmission of employers. Thompson (2014) studies the transmission of health and Cesarini et al. (2014) study the transmission of voting behaviour.
} 
We identify adopted children through an adoption indicator that is available in the RTB register from Statistics Sweden. From this register, we select all male foreignborn adoptees born between 1965 and 1978. In our sample, most adopted children came from South Korea (24\%), India (14\%), Chile (10\%), Thailand (9\%), Colombia $(7 \%)$, or Sri Lanka $(6 \%)$. In order to avoid the risk that some foreign-born adoptees are adopted by relatives, which would create a genetic link, we only include adoptees adopted by Swedish-born parents. By further restricting the sample to those who have enlisted in the military, and who have non-missing data on parental education and on our outcome measures, our sample of adoptees varies between 3,375 and 3,741, depending on the outcome studied.

Our twin sample consists of all children born to twin parents between 1950 and 1978 and who have enlisted to the military. ${ }^{9}$ In order to determine zygosity of the twins, we have merged our data with zygosity information from the Swedish Twin Registry. In this manner, we are able to determine zygosity for $82 \%$ of the parents in our dataset. ${ }^{10}$ Our dataset includes between 2,983 and 3,216 children of monozygotic twin parents, depending on the outcome studied.

Our third sample consists of the population of 'own-birth' sons born during the periods corresponding to the periods used in the adoptee and twin samples, i.e. 1950-1978. With these data, we are able to provide 'baseline' estimates for the population of sons with biological parents. Restricting the data of own-birth sons to those with non-missing observations on parental education gives us between 721,017 and 905,840 observations depending on the outcome studied.

In order to construct a measure of years of schooling for parents and their children, we use information on educational attainment from the Swedish education register (SUN codes). We use the standard way of coding these SUN codes into a years of schooling variable, i.e. where compulsory primary school, short upper secondary education, long upper secondary education, short university education, long university education, and a graduate education level are coded as 9, 11, 12, 14, 16, and 18 years of schooling.

In our empirical analyses, we focus on three set of outcomes: cognitive skills, non-cognitive skills, and health. These are measured at age 18, during the military enlistment. It should be noted that during our study period, in principle, every male Swedish citizen enlisted in the military when turning 18. Enlistment was mandatory and there is very little attrition in the data. Refusal to enlist leads to a fine, and eventually to imprisonment. Individuals are only exempted from enlistment if they are imprisoned, if they have ever been convicted for grave crimes (which mostly concerns violence-related and abuse-related crimes), or if they are in care institutions and are deemed to be unable to function in a war situation. During our study period,

\footnotetext{
${ }^{9}$ Note that for adopted children, the sample only includes those born 1965 and onwards. The reason is that there were almost no international adoptions taking place in Sweden before 1965.

${ }^{10}$ The twin registry determines zygosity based on survey questions regarding co-twin similarity. The method used has been found to classify twins with an accuracy of 95
} 
the annual cohort size of men turning 18 was about 50,000. Per cohort, around 1250 (i.e. $2.5 \%$ ) were exempted from enlistment. ${ }^{11}$

Cognitive skills are measured using a test similar to the AFQT in the USA. The test is called the Enlistment Battery 80 and includes four separate tests: Instructions, Synonyms, Metal Folding, and Technical Comprehension. The separate scores of these tests are aggregated into a standard composite measure calculated by the military enlistment service. Non-cognitive skills are measured through interviews carried out by certified psychologists employed by the Swedish army. The ultimate purpose of the interview is to evaluate the conscript's ability to perform military service and to function in a war situation. This is achieved through an assessment of the enlistee's psychological stability and endurance, capability of taking initiatives, responsibility, and social competence. The assessment results in a composite enlistment score of non-cognitive skills, ranging from 1 to 9 . The character traits assessed by the psychologists are similar to the traits usually included in measures of non-cognitive skills. The non-cognitive test score taken at the Swedish enlistment has been found to be a strong predictor of adult earnings, independently of cognitive skills (Lindqvist and Vestman 2011).

We consider two main health outcomes in our empirical analyses: height and a measure of overall health. The latter is a unidimensional global health measure, which is based on the severity of the individual's health conditions (both physical and mental) and which is used by the military to determine the enlistee's suitability for different types of military service. In our analyses, we transform their ordered categories into a 13-step scale, ranging from worst possible health to perfect health. The global health measure included in our data is expressed with letters from A to M (except 'I'), or ' $U$ ', ' $Y$ ', or ' $Z$ '. The closer to the start of the alphabet the letter assigned to the individual is, the better his general health status is considered to be; 'A' thus represents more or less perfect health, which is necessary for 'high mobility positions' (such as light infantry or pilot) and has been assigned to about $60 \%$ of all individuals for which there is non-missing data. For combat positions, individuals must have been assigned at least a ' $D$ ', and individuals with a ' $G$ ' or lower are only allowed to function in 'shielded positions'. Individuals that have been assigned a ' $Y$ ' or ' $\mathrm{Z}$ ' (in total $8 \%$ of the individuals) are not allowed to undergo education within the military. 'U' (assigned to less than $1 \%$ of all individuals) indicates that global health status has not been decided, and we treat this as missing. For simplicity, we use a linear measure of global health in our main analysis and transform ' $A$ ' into 13 , 'B' into 12 etc.; ' $\mathrm{Y}$ ' into 1 and ' $\mathrm{Z}$ ' into 0 .

The measure of height is taken by the staff at the enlistment offices and we standardise it in our empirical analyses. It is well known that an adult's height is related to many aspects of childhood health status (e.g. Bozzoli et al. 2009) and it has been referred to as "probably the best single indicator of his or her dietary and infectious

\footnotetext{
${ }^{11}$ Note also that the incentives to deliberately underperform at the enlistment tests are rather limited. The reason is that during our study period, the results of the tests had no impact on the probability of performing military service or not, since almost all people who enlisted during our study period also completed military service. Instead, the test results merely influenced the individual's placement within the army, meaning that poorer results typically led to a worse placement.
} 
disease history during childhood' (Elo and Preston 1992). Importantly, Lundborg et al. (2014a) found that height measured during the enlistment was an important predictor of earnings among adult Swedish men.

We believe that these two general health measures complement each other well; while our overall health measure gives a snapshot of the person's health at the moment of enlistment, height captures the accumulated health over the life course until the age of 18 .

In our empirical analyses, we also conduct some analyses of more specific health measures from the military enlistment records: physical work capacity, obesity, and hypertension. Physical work capacity is measured as the maximum number of watts attained when riding on a stationary bike (for about $5 \mathrm{~min}$ ) divided by weight in kilograms. An individual is classified as obese if his BMI $\left(\mathrm{kg} / \mathrm{m}^{2}\right)$ is higher than or equal to 30 . Hypertension is a binary variable indicating hypertension, based on the common medical thresholds for systolic and diastolic blood pressure.

Table 1 reports descriptive statistics for our main outcomes and for our three samples: own-birth sons, adopted sons, and own-birth sons with a monozygotic twin parent. In the table, we present the raw scores on the cognitive and non-cognitive tests, health tests, and height in centimeters, but in our empirical analyses, we normalise the measures to have a mean of zero and a standard deviation of one.

\section{Empirical model}

Next, we describe the two empirical strategies used to analyse the effect of parental schooling on child outcomes; the adoption and the twin design. The fundamental problem in establishing a causal effect of parental schooling is that the latter is associated with a myriad of unobserved factors that may have an independent effect on children. If this is the case, it is impossible to distinguish the effect of schooling from

Table 1 Descriptive statistics

\begin{tabular}{|c|c|c|c|c|c|c|}
\hline & \multicolumn{2}{|c|}{ Own-birth sons } & \multicolumn{2}{|c|}{ Adopted sons } & \multicolumn{2}{|c|}{ Sons of twins } \\
\hline & Mean & St. dev & Mean & St. dev & Mean & St. dev \\
\hline Cognitive ability & 5.15 & 1.92 & 4.22 & 1.91 & 5.24 & 1.83 \\
\hline Non-cognitive ability & 5.14 & 1.72 & 4.74 & 1.71 & 5.33 & 1.59 \\
\hline Health & 2.69 & 4.21 & 4.20 & 4.80 & 2.22 & 3.69 \\
\hline Height $(\mathrm{cm})$ & 179.30 & 6.48 & 170.20 & 6.59 & 179.68 & 6.19 \\
\hline Age at adoption & & & 1.69 & 1.92 & & \\
\hline Paternal education & 10.55 & 3.10 & 12.69 & 2.73 & 10.56 & 3.12 \\
\hline Maternal education & 10.50 & 2.86 & 12.80 & 2.61 & 10.63 & 2.71 \\
\hline
\end{tabular}

This table reports descriptive statistics. Cognitive and non-cognitive test scores are measured between 1 and 9, health between 0 and 13. Height is measured in centimeters. In the empirical analyses, these measures are normalised to have a mean of zero and a standard deviation of one 
that of these unobserved factors, leading to a biased schooling coefficient. The adoption and the twin design both aim to implicity control for such unobserved factors and by doing so arrive at a causal interpretation of the schooling coefficient.

\subsection{The adoption approach}

We first describe the adoption design and its pros and cons. In our context, the design relates the schooling of adoptive parents to outcomes of the adopted child. Given that there is no biological relationship between the parent and the adopted child, this ensures that there is no genetic relationship between the parent and the child. If unobserved variables that are related to the schooling of the parent, and affect the child, are mostly of genetic nature, the adoption design solves this type of omitted variables problem. As we discuss below, this is normally a strong assumption and the estimate of parent's schooling should be interpreted as the effect of schooling and all other factors that are correlated with the adoptive parent's schooling, and that have an effect on the adopted child's outcomes, net of the genetic transmission (Holmlund et al. 2011). This is usually referred to as the 'nurture' effect.

The typical reduced form equation used to estimate the intergenerational transmission of human capital from an adoptive parent ap to an adopted child $a c$ can be written as follows:

$$
Y^{\mathrm{ac}}=\alpha_{A D}+\delta_{A D} S^{\mathrm{ap}}+\Gamma_{A D} g^{\mathrm{bp}}+\gamma_{A D} f^{\mathrm{ap}}+v^{\mathrm{ac}}
$$

In this paper, $Y^{\mathrm{ac}}$ represents the adopted child's outcomes, such as cognitive and non-cognitive skills and health, whereas $S^{\text {ap }}$ represents the schooling of the adoptive parent. Moreover, $g^{\text {bp }}$ represents any genetic endowments that are passed on from the biological parent to the child, whereas $f$ ap represents any non-genetically transmitted characteristic of the adoptive parent other than schooling. Unobserved child-specific factors are denoted $v^{\mathrm{ac}}$. The $\delta_{\mathrm{AD}}$ coefficient measures the causal effect of adoptive parental education, $S^{\mathrm{ap}}$, on child outcomes. The $\Gamma_{\mathrm{AD}}$ and $\gamma_{\mathrm{AD}}$ coefficients measure the extent to which genetic endowments and non-genetic endowments are transmitted to the adopted child.

In this specification, only the education of one of the adoptive parents is included but in our empirical analysis, we will also employ specifications where we include the spouse's education. In order to identify $\delta_{\mathrm{AD}}$, the adoption literature relies on two standard assumptions. First, adopted children are assumed to be randomly allocated to their adoptive parents. If the adoption agency instead matched the adoptive child with the adoptive parents, or if the education of the adoptive parents somehow is related to characteristics of the biological parents, an artificial genetic link may be constructed and $\operatorname{cov}\left(S^{\mathrm{ap}}, g^{\mathrm{bp}}\right) \neq 0$. This would also be the case if adoptive parents were able to choose who to adopt and if well-educated parents then choose healthier children or children with better innate skills. ${ }^{12}$ Besides controlling for observable

\footnotetext{
${ }^{12}$ Another worry is that the parents or the adoption centres in the home countries of the adoptees will choose adoptive parents based on certain characteristics. It is very common, however, that the children given up for adoption are children that have been abandoned by their mother, in which case the mother is
} 
characteristics of the adoptees, through the inclusion of country of adoption fixed effects and age at adoption fixed effects, we will conduct a sensitivity analysis in order to examine whether child-parent matching is a problem in our study. It should be noted that adoptive parents in Sweden are not able to choose a particular child for adoption. $^{13,14}$

The second assumption required in the adoption design is that any non-genetic characteristics of the parents that also directly influences the adopted child are unrelated to parental schooling, i.e. that $\operatorname{cov}\left(S^{\mathrm{ap}}, f^{\mathrm{ap}}\right) \neq 0$. There is nothing in the adoption design that guarantees this and one can only speculate on the likely direction of the bias that arises from violating this assumption. For child-rearing skills, for instance, it is not clear a priori if such skills are negatively or positively related to parental education (Björklund et al. 2006). If there is a trade-off between investing in child-rearing skills and schooling, they may be negatively related. On the other hand, education is often assumed to be related to an increased efficiency of household production, which may include child-rearing. In any case, if the second assumption is violated, the estimated 'nurturing' effect would include both the effect of parental education and any other non-genetic factors that are related to both parental schooling and child outcomes.

The external validity of adoption-based estimates may be threatened for a number of reasons. For instance, adoptees may be less affected by parental nurturing if they face emotional problems from adoption. Similarly, nurturing may be less effective if adoptees are already hurt by adverse conditions during pregnancy and during the first years of life (i.e. prior to adoption). Nurturing skills may, however, be greater among adoptive parents, since they are screened prior to adoption. Also, they are more highly educated on average (as shown in Table 1). On the other hand, the same type of screening also means that there may be less variation in nurturing skills within the group of adoptive parents, which would push the estimated nurturing effect downwards. One also needs to recognise the possibility that adoptive parents treat

unknown (SOU 2003). Even if the mother is known, it seems that she has little influence over the selection of adoptive parents, once she has given a written approval to the adoption organisation.

${ }^{13}$ Instead, a strict procedure is followed, where the parents seeking to adopt first have to seek permission from the social authorities, who will undertake a thorough investigation about the person's or couple's ability to take care of an adopted child (SOU 2003). If granted permission, the couple can contact a government-accredited adoption organisation and file an application to adopt. By choosing a particular organisation, which often specialises in children from particular countries, the parents are able to choose what country to adopt from. They are also able to state a preference regarding the gender and age of the child, although there is no guarantee that this preference will be fulfilled. Thus, the parents may influence certain characteristics of the adoptive child, but these characteristics are observable to us and are controlled for in the empirical analyses.

${ }^{14}$ Holmlund et al. (2011) used data on international adoptees in Sweden and found some weak evidence of selection of adoptees. For instance, more highly educated mothers seemed to prefer older children and boys. The estimated effects were very small, however, and when controlling for these observable factors, the estimated intergenerational associations hardly changed. 
their adopted children differently from how they treat, or would have treated, their biological children. We will investigate these issues in a sensitivity analysis. ${ }^{15}$

\subsection{The twin approach}

The intuition behind the twin design is to control for important unobserved factors by comparing outcomes for individuals who share genetics and, to a large part, environmental background, but who differ in terms of schooling. In our context, the influence of such unobserved factors is removed by relating differences in schooling between monozygotic twin parents to differences in their children's skills and health. If the unobserved factors that are related to parents' schooling, and that also affect children, mostly reflect environmental factors shared by twins, such as parental background and behaviours, or are of genetic nature, we obtain an unbiased effect of parental schooling. This is a strong assumption, however, and below, we discuss possible violations of it. Using the twin design, we can write the intergenerational transmission equation as follows:

$$
\Delta Y^{\mathrm{c}}=\delta_{T W} \Delta S^{\mathrm{p}}+\Gamma_{T W} \Delta g^{\mathrm{p}}+\gamma_{T W} \Delta f^{\mathrm{p}}+\Delta v^{\mathrm{c}} .
$$

Here, $\Delta Y^{\mathrm{c}}$ denotes the difference within twin pairs in the outcome studied, $\Delta S^{\mathrm{p}}$ denotes the corresponding difference in parental schooling, $\Delta g^{\mathrm{p}}$ and $\Delta f^{\mathrm{p}}$ denote differences in genetic and non-genetic endowments, and $\Delta v^{\mathrm{c}}$ denotes differences in other unobservable characteristics within twin pairs. When using only data on monozygotic twin parents who are genetically identical, we difference out genetic endowments and have that $\Delta g^{\mathrm{p}}=0$. In this specification, we allow the effect of parental education to also include effects that run through assortative mating. This means that we still get an unbiased estimate of the schooling of the twin parent but that the effect also includes the endowments and schooling of the spouse. We will contrast the results obtained using this specification to those obtained when controlling for the education of the spouse. Since it is not possible to difference out the endowments that vary between the spouses, however, the estimates where we control for spousal education will most likely be upward biased. The reason is that more highly educated parents are also more likely to marry a partner with favourable endowments, generating a positive correlation between the education of the twin parent and the error term.

In order for the twin approach to provide an estimate of the causal effect, a number of additional assumptions need to be made. In our case, the most important assumption is that schooling differences between identical twin parents are unrelated to differences in non-genetic characteristics that may also affect the outcomes of the child. To achieve this, the twin literature also assumes that $\Delta f^{\mathrm{p}}=0$ within twin

\footnotetext{
${ }^{15}$ If adopted children has lower ability on average, as Table 1 suggests, and if there are positive interactions between genes and environment, adopted children may also benefit less from an improved environment. Since we have no information on the biological parents of the adoptees, we cannot investigate this possibility.
} 
pairs. Thus, by differentiating out $g^{\mathrm{p}}$ and $f^{\mathrm{p}}$, one may obtain an estimate of the causal effect $\delta_{T W}$.

The assumption that schooling differences within twin pairs are unrelated to differences in unobserved non-genetic characteristics has been questioned by, for instance, Bound and Solon (1999). It would fail, for instance, if schooling differences within twin pairs are associated with differences in ability, parenting skills, or birth weight. There is some evidence suggesting that birth weight differences between twins may be associated with schooling differences (Black et al. 2007). The estimated effects are usually very small however. Royer (2009) finds a small significant effect, where increasing birth weight by $250 \mathrm{~g}$ (which would be quite a policy achievement), only leads to 0.03-0.04 of a year of additional schooling. Black et al. (2007) find that a $10 \%$ increase in birth weight increases the probability of high school completion by just 1 percentage point. Behrman and Rosenzweig (2004) find a slightly larger effect with a 1 pound (453 g) increase in birth weight increasing schooling by a third of a year. Miller et al. (2005), using data from the Australian twin registry, find no significant relationship between birth weight and schooling, however.

Ability differences may also exist between monozygotic twins. Sandewall et al. (2014) used similar data as ours and showed that IQ test differences between twins predicted later schooling. If the same IQ test differences directly affect the children's skills and health, omitting IQ from the regression would bias our results. Since we only have IQ test information for a very small subsample of fathers, we cannot test for this, but we note that Amin et al. (2015), using a larger sample of Swedish twins, showed that including fathers' IQ in an intergenerational schooling regression did not affect the schooling coefficient. ${ }^{16}$ To the extent that there remain important omitted characteristics between twins, however, the estimated coefficient on parental education should be interpreted as the combined effect of parent's schooling and all other factors that are correlated with parent's schooling and who also have an independent effect on child's schooling, net of genetic transmission.

Another assumption commonly made in the twin design is that measurement errors are small. As shown by Griliches (1979), the downward bias induced by normally distributed measurement errors will be exaggerated when using sibling or twin fixed effects models. Any reduction in the estimated coefficients when imposing sibling fixed effects may therefore be caused by the more severe downward bias resulting from measurement errors, rather than from removal of twin pair-specific

\footnotetext{
${ }^{16}$ Bias may also be induced if there is differential treatment of twins by parents. For instance, parents may try to compensate for, or amplify differences between the twins by investing more or less in the less able or less healthy twin. Such compensating behaviour would for instance be present in a model in which the returns to child investments are greater for the least able child in the family and the parents only care about maximising the returns to the investments (Becker and Tomes 1976; Behrman et al. 1982; Rosenzweig and Schultz 1982). Results from a small twin-based literature, using various measures of parental inputs, do not suggest that parents systematically reinforce or compensate for early life insult, however (see for instance Royer 2009 and Almond and Currie 2011). Isacsson (1999) finds no relation between psychological instability early in life, being an imperfect proxy of parental rearing skills, and years of schooling among Swedish twins.
} 
Table 2 Estimates of the relationship between parental education level and sons' outcomes

\begin{tabular}{|c|c|c|c|c|}
\hline & \multicolumn{4}{|c|}{ Years of schooling } \\
\hline & \multirow[t]{2}{*}{ Own-birth } & \multirow[t]{2}{*}{ Adopted } & \multicolumn{2}{|l|}{ MZ twins } \\
\hline & & & OLS & $\mathrm{FE}$ \\
\hline Paternal & 0.275 & 0.051 & 0.285 & 0.070 \\
\hline education & $(0.001)^{* * *}$ & $(0.012)^{* * *}$ & $(0.017)^{* * *}$ & $(0.037)^{*}$ \\
\hline$N$ & 753,601 & 3540 & 1303 & 1303 \\
\hline Maternal & 0.283 & 0.022 & 0.272 & 0.033 \\
\hline education & $(0.001)^{* * *}$ & $(0.012)^{*}$ & $(0.017)^{* * *}$ & $(0.035)$ \\
\hline$N$ & 887,384 & 3540 & 1982 & 1982 \\
\hline
\end{tabular}

Each coefficient represents a separate regression. The dependent variable is years of schooling. For adopted children, age at adoption and country of birth fixed effects are included. Standard errors are shown below the coefficients. $* * * p<0.01, * * p<0.05, * p<0.1$

unobserved heterogeneity. Since we rely on register data on education, we believe that measurement error is less of a concern. ${ }^{17,18}$

\section{Results}

\subsection{Transmission of schooling: replication}

We start our empirical analysis by replicating previous estimates of the transmission of education across generations, using both the adoption and twin design. Table 2 shows regressions where the independent variable is the parent's obtained number of years of schooling and where the dependent variable is the child's years of schooling. In subsequent sections, we focus on the specific mechanisms through which the transmission occurs.

In column 1, an additional year of parental schooling is associated with about 0.3 year of schooling for own-birth children. When we focus on adoptees, as shown in column 2, the estimate for fathers' schooling decreases substantially but remains significant at 0.05 years. For mothers, the estimate becomes smaller, at 0.02 . We obtain a similar pattern using the twin design (column 4); here, we find that 1 additional year of fathers' schooling increases the child's schooling by 0.07 years where the corresponding estimate for mothers is 0.03 .

\footnotetext{
${ }^{17}$ Holmlund et al. (2008) addressed the measurement error problem in the Swedish data using the approach suggested by Ashenfelter and Krueger (1994): instrumenting the education measure with another, independent, measure of the same education did not affect the results. Moreover, Holmlund et al. (2011) found the reliability ratio in the education measure to be high.

${ }^{18}$ Downward bias would also occur if children of twin parents, i.e. cousins, interact more frequently, since they may then be affected by their uncle's or aunt's education.
} 
We can compare our estimates to previous studies that have used Swedish data and similar designs. Our twin estimates are close to the estimates obtained by Amin et al. (2015), although they found somewhat larger estimates for mothers' schooling. Holmlund et al. (2011) found significant estimates for both mothers and fathers but did not distinguish between MZ and DZ twins. Our adoption estimates are close to the ones obtained by Holmlund et al. (2011) although their estimates for mothers' schooling were a bit larger. Taken together, our estimates on the transmission of schooling are not very different from previous estimates in the literature, suggesting that the results below on potential mechanisms is relevant also for the broader literature on the transmission of schooling.

\subsection{Adopted sons}

We next estimate the relationship between parental education and child outcomes for own-birth sons and adopted sons. Table 3 shows the results, where separate regressions for maternal and paternal schooling are estimated. Table 4 shows the corresponding results when controlling for the spouse's education. All regressions on adoptees include fixed effects for age at adoption and country of origin.

Focusing first on the results for cognitive and non-cognitive skills as outcomes, the significant estimates for own-birth sons suggest that 1 additional year of paternal schooling increases cognitive and non-cognitive skills by 0.099 and 0.057 of a standard deviation, respectively. The corresponding estimates for maternal education are almost identical, being 0.096 and 0.056 , respectively. Moving on to the adoptees, the estimates are substantially lower. Moreover, the relative importance of paternal versus maternal years of schooling changes. For cognitive skills, the estimate for paternal education now decreases to 0.027 , while the corresponding estimate of maternal education decreases to 0.014 , both being statistically significant at the $5 \%$ level.

Similar patterns as those for cognitive skills are obtained for the effect of the adoptive father's education on non-cognitive skills, where the point estimate is reduced to 0.017 , while the corresponding estimate for the mother's education is close to zero and statistically insignificant. When we control for the spouse's education in the regressions on cognitive and non-cognitive skills, as shown in Table 4, the effect of the adoption mother's education on either type of skill approaches zero, whereas the effects of the adoption father's education on cognitive and non-cognitive skills remain almost unchanged. Our results for adoptees thus suggest that only the education of the father has a nurturing impact on the child's cognitive and non-cognitive test scores. For mothers, we interpret the association between the mother's education and the children's skills to mainly reflect inherited abilities and assortative mating. ${ }^{19}$

We can only speculate on why only paternal education matters. One possible explanation would be that there exists a negative correlation between child-rearing

\footnotetext{
${ }^{19}$ Another way to control for assortative mating, and at the same time obtain more precision, is to estimate the effect of the sum of both parents' schooling. When we do so, as shown in Table A1, we obtain positive and significant estimates, where the magnitude of the estimates, unsurprisingly, lies in between the estimates for mothers and fathers.
} 
Table 3 Estimates of the relationship between parental education level and sons' outcomes

\begin{tabular}{|c|c|c|c|c|c|c|c|c|}
\hline & \multicolumn{4}{|c|}{ Cognitive skills } & \multicolumn{4}{|c|}{ Non-cognitive skills } \\
\hline & \multirow[t]{2}{*}{ Own-birth } & \multirow[t]{2}{*}{ Adopted } & \multicolumn{2}{|l|}{ MZ twins } & \multirow[t]{2}{*}{ Own-birth } & \multirow[t]{2}{*}{ Adopted } & \multicolumn{2}{|l|}{ MZ twins } \\
\hline & & & OLS & FE & & & OLS & $\mathrm{FE}$ \\
\hline Paternal & 0.099 & 0.027 & 0.097 & 0.044 & 0.057 & 0.017 & 0.061 & 0.041 \\
\hline education & $(0.000)^{* * *}$ & $(0.006)^{* * *}$ & $(0.008)^{* * *}$ & $(0.019)^{* *}$ & $(0.000)^{* * *}$ & $(0.006)^{* *}$ & $(0.009) * * *$ & $(0.021)^{*}$ \\
\hline$N$ & 748,598 & 3692 & 1245 & 1245 & 721,017 & 3375 & 1165 & 1165 \\
\hline Maternal & 0.096 & 0.014 & 0.100 & 0.050 & 0.056 & 0.003 & 0.055 & 0.019 \\
\hline education & $(0.000)^{* * *}$ & $(0.006)^{* *}$ & $(0.008)^{* * *}$ & $(0.017)^{* * *}$ & $(0.000)^{* * *}$ & $(0.007)$ & $(0.008)^{* * *}$ & $(0.019)$ \\
\hline \multirow[t]{4}{*}{$N$} & 880,791 & 3692 & 1928 & 1928 & 851,128 & 3375 & 1818 & 1818 \\
\hline & \multicolumn{4}{|l|}{ Health } & \multicolumn{4}{|l|}{ Height } \\
\hline & \multirow[t]{2}{*}{ Own-birth } & \multirow[t]{2}{*}{ Adopted } & \multicolumn{2}{|l|}{ MZ twins } & \multirow[t]{2}{*}{ Own-birth } & \multirow[t]{2}{*}{ Adopted } & \multicolumn{2}{|l|}{ MZ twins } \\
\hline & & & OLS & FE & & & OLS & $\mathrm{FE}$ \\
\hline Paternal & 0.011 & 0.009 & 0.003 & -0.014 & 0.014 & 0.011 & 0.040 & 0.018 \\
\hline education & $(0.000)^{* * *}$ & $(0.006)$ & (0.009) & $(0.021)$ & $(0.000)^{* * *}$ & $(0.006)^{*}$ & $(0.009)^{* * *}$ & $(0.019)$ \\
\hline$N$ & 768,941 & 3631 & 1303 & 1303 & 748,295 & 3741 & 1228 & 1228 \\
\hline Maternal & 0.004 & 0.011 & 0.004 & 0.042 & 0.020 & 0.005 & 0.032 & 0.017 \\
\hline education & $(0.000) * * *$ & $(0.006)^{*}$ & $(0.008)$ & $(0.019)^{* *}$ & $(0.000)^{* * *}$ & $(0.006)$ & $(0.009)^{* * *}$ & $(0.015)$ \\
\hline$N$ & 905,840 & 3631 & 1982 & 1982 & 883,609 & 3741 & 1913 & 1913 \\
\hline
\end{tabular}

Each coefficient represents a separate regression. The dependent variables are the son's cognitive skills, non-cognitive skills, health, and height at age 18. For adopted children, age at adoption and country of birth fixed effects are included in the model. Standard errors are shown below the coefficients. *** $p<0.01$, $* * p<0.05, * p<0.1$

skills and education among mothers but not among fathers. ${ }^{20}$ Another explanation could be that the result reflects specialisation within the household, where fathers take a greater responsibility for helping with tasks that improve the children's cognitive and non-cognitive skills, whereas mothers take a greater responsibility for other household work. Yet another explanation could be that there is a stronger correlation between education and income for fathers than for mothers, so that the effect of

\footnotetext{
${ }^{20} \mathrm{~A}$ downward bias would also arise if there is a negative correlation between education and certain favourable unobserved characteristics in the sample of adoptive parents (Black and Devereux 2010). The reason is that adoptive parents who are allowed to adopt despite poor observable characteristics are likely to have better on average unobserved characteristics that compensate for their poor observable characteristics. This would imply that the estimated effect for the sample of adoptive parents is downward biased. If the negative correlation between education and favourable unobserved characteristics is stronger for mothers than fathers, one reason being that the screening procedure prior to adoption may put more emphasis on maternal characteristics, this could explain why the estimated effects are smaller for mothers. There is nothing in the formal guidelines for adoption, however, which supports such a differential treatment of males and females.
} 
Table 4 Estimates of the relationship between parental education level and son's outcomes when accounting for assortative mating

\begin{tabular}{|c|c|c|c|c|}
\hline & Cognitive & Non-cognitive & Health & Height \\
\hline & \multicolumn{4}{|c|}{ Panel A: adopted sons } \\
\hline \multirow[t]{2}{*}{ Paternal education } & 0.027 & 0.021 & 0.004 & 0.011 \\
\hline & $(0.006) * * *$ & $(0.007)^{* *}$ & $(0.007)$ & $(0.006)^{*}$ \\
\hline \multirow[t]{2}{*}{ Maternal education } & -0.001 & -0.008 & .009 & -0.001 \\
\hline & $(0.007)$ & $(0.008)$ & $(0.007)$ & $(0.007)$ \\
\hline \multirow[t]{2}{*}{$N$} & 3692 & 3375 & 3253 & 3741 \\
\hline & \multicolumn{4}{|c|}{ Panel B: sons of MZ twins } \\
\hline \multirow[t]{2}{*}{ Paternal (twin) education } & 0.033 & 0.041 & -0.014 & 0.115 \\
\hline & $(0.019)^{*}$ & $(0.022)^{*}$ & $(0.021)$ & $(0.119)$ \\
\hline \multirow[t]{2}{*}{ Maternal education } & 0.056 & 0.001 & -0.002 & 0.000 \\
\hline & $(0.016) * * *$ & $(0.019)$ & $(0.018)$ & $(0.102)$ \\
\hline$N$ & 1245 & 1165 & 1303 & 1228 \\
\hline \multirow[t]{2}{*}{ Maternal (twin) education } & 0.043 & 0.013 & 0.040 & 0.014 \\
\hline & $(0.017)^{* * *}$ & $(0.019)$ & $(0.019)^{* *}$ & $(0.016)$ \\
\hline \multirow[t]{2}{*}{ Paternal education } & 0.052 & 0.038 & 0.017 & 0.022 \\
\hline & $(0.013)^{* * * *}$ & $(0.016)^{* *}$ & $(0.015)$ & $(0.013)^{*}$ \\
\hline$N$ & 1928 & 1818 & 1982 & 1913 \\
\hline
\end{tabular}

The dependent variables are the son's cognitive skills, non-cognitive skills, health, and height at age 18 . Each coefficient represents a separate regression. The models in Panel A include fixed effects for age at adoption and country of birth. The models in Panel B include twin pair fixed effects. Standard errors are shown below the coefficients. $* * * p<0.01, * * p<0.05, * p<0.1$

paternal education also picks up the effect of income to a greater extent. ${ }^{21}$ We can test this by including controls for income in the regressions. This only marginally affected the estimates for parental education and the decline in the size of the coefficients was almost identical for mothers and fathers. ${ }^{22}$ This is similar to the results obtained in Hægeland et al. (2010), where educated mothers work more but where no detrimental effect on children's education is found. Role model effects would also be possible, where sons look up more to fathers than to mothers. A causal effect would then be implied if father's schooling act as a standard for the child, and while there is limited evidence of such role model effects in the previous literature, Amin et al. (2015) found some evidence for it using a twin design and studying the transmission of schooling.

\footnotetext{
${ }^{21}$ Yet another explanation for this result would be that measurement errors are more severe for the measure of maternal years of schooling. Since our measures are based on register data, we see no reason why this would be the case in our study. Moreover, Holmlund et al. (2008) report that the reliability ratio for education in these register is 0.95 for both mothers and fathers.

${ }^{22}$ For cognitive skills, the effects of paternal and maternal education declined to 0.022 and 0.009 when controlling for income. The corresponding estimates for non-cognitive skills were 0.013 and 0.000 .
} 
The relative importance of paternal versus maternal education is less clear when we instead consider health outcomes. Although paternal education seems to matter more than maternal education for the overall health of their own-birth sons, this result does not hold up in the sample of adoptees. Here, maternal education is associated with a slightly greater increase in health and the effect is significant at the $10 \%$ level, although it should be noted that the difference in point estimates between mothers and fathers is not significant. When accounting for spouse's education, however, the point estimates of both maternal and paternal education decrease in magnitude and become insignificant. For height, paternal education seems to matter somewhat more and the estimate is still significant when accounting for spousal education. ${ }^{23,24}$

The absence of a clear effect of maternal education on general measures of children's health may seem surprising, given the prominent role it is often believed to have for children's health (Haveman and Wolfe 1995). Our result may of course suggest that the relation is driven mainly by genetic factors. Another possibility would be that maternal education is ineffective in 'producing' child health for adopted children or at least for children who were adopted at a later age. By comparing the effect of maternal education for those adopted late to the effect on those adopted at an early age, we can get some indications whether nurturing is less effective for those adopted late and, thus, if maternal education is affecting the health of those adopted early. ${ }^{25}$ The estimates in Table 5 suggest so. For health, the effect of maternal education is large and significant for those adopted before the age of 1 , whereas the effect is small and insignificant for those adopted later. The effect is similar whether or not controlling for spouse's education. For fathers, however, the effect of education becomes insignificant when controlling for spouse's education. Thus, when restricting the sample to those adopted early, our estimates confirm the common claim that maternal education matters more for children's health than paternal education. This result also supports the idea that parental education has less of an effect on health if the child had been exposed to adverse living conditions early in life. ${ }^{26}$

We obtain similar results for children's cognitive and non-cognitive skills (see Table 5). The effect of paternal education on these skills is at least double in magnitude, and significant, for those adopted before the age of 1 in the specifications

\footnotetext{
${ }^{23}$ When we estimate the effect of the sum of both parents' schooling, we obtain imprecise estimates (Table 8).

${ }^{24}$ We have also investigated some more specific health measures that are available in the enlistment data. In Table 9 in the Appendix we show results for physical capacity, measured as maximum oxygen uptake, obesity, and hypertension. Both mothers' and fathers' schooling increase physical capacity and reduce the incidence of obesity but have no effects on hypertension. The point estimates are similar in magnitude between mothers and fathers.

${ }^{25}$ This would suggest that there are critical periods in development, where the absence of certain inputs at certain development phases make it difficult for a child to catch up at a later stage. Evidence from Romanian adoptees adopted in the UK, for instance, suggests that if the adoption took place during the first 6 months of life, the catch-up in terms of height and IQ was almost complete (Rutter et al. 1998). For those adopted later, the catch-up was less, but still substantial. Similar results for height were obtained in van den Berg et al. (2014) using data on siblings immigrating to Sweden at different ages.

${ }^{26}$ For our other health measure, height, the estimates were not greatly affected by restricting the sample to those adopted before the age of 1 .
} 
Table 5 Estimating the relationship between parental education level and sons' outcomes by age at adoption

\begin{tabular}{|c|c|c|c|c|c|c|c|c|}
\hline & \multicolumn{4}{|c|}{ Age at adoption $\geq 1$} & \multicolumn{4}{|c|}{ Age at adoption $<1$} \\
\hline & Cognitive & Non-cognitive & Health & Height & Cognitive & Non-cognitive & Health & Height \\
\hline \multicolumn{9}{|c|}{ Not controlling for spouse's education } \\
\hline Paternal & .020 & .008 & .001 & .012 & .034 & .030 & .020 & .007 \\
\hline education & $(.007)^{* * * *}$ & $(0.008)$ & $(.007)$ & $(.007)^{*}$ & $(.010)^{* * *}$ & $(.012)^{* *}$ & $(.011)^{*}$ & $(.010)$ \\
\hline Maternal & .014 & -.003 & -.001 & .008 & .014 & .017 & .034 & -.0003 \\
\hline education & $(.017)^{* * *}$ & $(.008)$ & $(.008)$ & $(.007)$ & .014 & $(.012)$ & $(.011)^{* * *}$ & $(.011)$ \\
\hline$N$ & 2555 & 2341 & 2512 & 2587 & 1137 & 1034 & 1141 & 1154 \\
\hline \multicolumn{9}{|c|}{ Controlling for spouse's education } \\
\hline Paternal & 0.018 & 0.012 & 0.002 & 0.011 & 0.036 & 0.029 & 0.005 & 0.011 \\
\hline education & $(.008) * *$ & (0.009) & $(0.009)$ & $(0.008)$ & $(0.012)^{* * *}$ & $(0.013)^{* *}$ & $(0.013)$ & $(0.012)$ \\
\hline Maternal & 0.005 & -0.009 & -0.002 & 0.002 & -0.004 & 0.001 & 0.031 & -0.008 \\
\hline education & $(0.008)$ & $(0.009)$ & $(0.009)$ & $(0.008)$ & $(0.012)$ & $(0.014)$ & $(0.013)^{* *}$ & $(0.012)$ \\
\hline$N$ & 2555 & 2341 & 2512 & 2587 & 1137 & 1034 & 1141 & 1154 \\
\hline
\end{tabular}

The dependent variable is shown in the top of the column. Each coefficient represents a separate regression. Standard errors in parenthesis. $* * * p<0.01, * * p<0.05,{ }^{*} p<0.1$

that control for spouse's education. This is in line with evidence of the importance of early-life inputs for the development of both cognitive and non-cognitive skills (Knudsen et al. 2006). For maternal education, the estimates are small and insignificant whether or not one restricts the sample to those adopted early. In sum, restricting the sample to adoptees that are more likely to be affected by parental education provided clear patterns regarding the role of maternal and paternal education. Clearly, maternal education matters more for child health, at least for those adopted at early ages, whereas paternal education matters more for child skills. ${ }^{27}$

How does our results regarding the relative importance of paternal versus maternal education match up with previous adoption-based studies on the transmission of education across generations? Adoption studies in general tend to find that the effect of mother's schooling is smaller than the effect of father's schooling when spouse's schooling is controlled for (e.g. Plug 2004; Björklund et al. 2006). Our results suggest that part of the reason for this gender pattern may be that the education of adoptive mothers matters less than the education of adoptive fathers for the development of the children's skills.

As discussed in the methods section, a crucial assumption in the adoption design is that adopted children are randomly allocated to their adoptive parents. Before proceeding with the results for twins, we will shed some light on the credibility of this

\footnotetext{
${ }^{27}$ We also tried finer divisions of age at adoption but above the age of 3 , the sample size becomes small and the estimates imprecise.
} 
Table 6 Estimating the relationship between parental education level and country of birth and age at adoption

\begin{tabular}{lccccccc}
\hline \multicolumn{7}{l}{ Country of origin } \\
\cline { 2 - 8 } & Chile & Columbia & India & South Korea & Sri Lanka & Thailand & Age adopted \\
\hline Paternal & 0.002 & 0.003 & 0.001 & -0.007 & -0.005 & -0.002 & -0.016 \\
education & $(0.002)$ & $(0.002)^{*}$ & $(0.002)$ & $(0.003)^{* *}$ & $(0.002)^{* * *}$ & $(0.002)$ & $(0.013)$ \\
Maternal & -0.003 & 0.005 & 0.001 & -0.012 & 0.003 & 0.000 & 0.004 \\
education & $(0.002)$ & $(0.002)^{* *}$ & $(0.003)$ & $(0.003)^{* * *}$ & $(0.002)^{*}$ & $(0.002)$ & $(0.014)$ \\
\hline
\end{tabular}

The dependent variable is shown at the top of the column. Each coefficient represents a separate regression. Standard errors in parenthesis. $* * * p<0.01, * * p<0.05, * p<0.1$

assumption by regressing parental education on some observable characteristics of the adopted children: country of origin and age at adoption. The results, reported in Table 6, suggest that some matching appears to be taking place with respect to country of origin, since 6 out of 12 coefficients from the regressions come out as significant. The magnitudes of the coefficients are quite small, however. These results suggest, for instance, that parental education is positively and significantly related to the probability of adopting a child from Colombia. On the other hand, there is a negative correlation between parental education and the probability of being adopted from South Korea. Since children from South Korea outperform Swedish-born children in some of the enlistment tests, this rather suggests that, if anything, some negative selection is present.

Further evidence that the magnitude of the matching is limited is revealed by the fact that including country of birth fixed effects in the regressions in Table 3 does not change the results to any important extent. In fact, some of the resulting estimates for the adopted children become somewhat stronger in magnitude, which is what one would expected if there is a negative relation between parental education and the probability of adopting a child from 'high-quality' countries.

For age at adoption (see last column of Table 6), we do not find any significant relationship with parental education. In sum, we believe that the results presented in Table 6, do not suggest any problematic matching that we cannot deal with. Remember also that parents are not able to choose a particular child, besides stating preferences for gender and country of birth, which we observe, and that parents who give children away for adoption are normally not allowed to state preferences for adoptive parents. We also note that our results on potential non-random allocation of adoptees are similar to the results found in Holmlund et al. (2011), where there was no evidence of any important parent-child matching. ${ }^{28}$

\footnotetext{
${ }^{28}$ Recall also that Sacerdote (2007) and Björklund et al. (2006) explicitly controlled for potential selective placement of adoptees and still found that the adoptive parent's education had an effect on their children's education.
} 


\subsection{Sons with a monozygotic twin parent}

We continue to explore the intergenerational transmission of human capital using the twin design. The results are shown in Table 3, where we also include the OLS results for the twin sample in order to get some idea about the representativeness of the twin sample. Ideally, the OLS estimates should not differ by much compared to the result for the main sample of own-birth children, which is also what most of the results in Table 3 suggest. For cognitive skills, for instance, the own-birth estimates of paternal and maternal education are 0.099 and 0.096 , which is very similar to the OLS estimates obtained for the twin sample of 0.097 and 0.100 .

Moving on to the twin fixed-effect results, and starting with cognitive skills, the results suggest a similar 'nurturing' effect of both maternal and paternal education of 0.050 and 0.044 , respectively. For fathers, this estimate is rather similar to the corresponding estimate obtained in the sample of adoptees. For mothers, the difference is larger. The results for cognitive skills do not change much when controlling for spousal education, as shown in Table 4, or when estimating the effect of the sum of parental schooling, as shown in Table 8. Note that this result differs from the result obtained for adoptive mothers, where the effect approached zero when accounting for the spouse's education.

The results for non-cognitive skills are also much in line with the results obtained for adoptees. While the OLS estimates on the twin sample suggest an equal effect of maternal and paternal educations on their children's non-cognitive skills, the fixed effects estimates again suggest that paternal education matters more. An additional year of schooling increases the non-cognitive test results by 0.041 , whereas the corresponding estimate for mothers is 0.019 and insignificant. Accounting for the spouse's education does, again, not change this pattern.

For our overall health measure, the twin-based estimates suggest that the mother's education matters more. Moreover, the estimated coefficient differs substantially from that for fathers, which is small, insignificant, and has the opposite sign. For height, the estimates are roughly halved in magnitude when imposing fixed effects and similar, but imprecisely measured, for both twin fathers and mothers. None of these results change to any dramatic extent when accounting for the spouse's education or when estimating the effect of the sum of parental schooling (Table 8). ${ }^{29}$

Again, we find a rather pronounced pattern regarding the importance of maternal and paternal education. Here, as was the case for the adoptees, there is a tendency towards maternal education being more important for children's health outcomes, whereas father's education seems more important for the development of skills. Does this pattern line up well with previous twin-based estimates of the transmission of education across generations? In Amin et al. (2015), the effect of maternal and paternal education on son's education was found to be roughly equal, between 0.05 and 0.06 , when using a sample of MZ twin parents in Sweden and focusing on years of schooling. When accounting for assortative mating, however, the estimates became

\footnotetext{
${ }^{29}$ Table 9 in the Appendix show twin estimates of the effect of parental schooling on physical capacity, obesity, and hypertension. None of the estimates reach statistical significance.
} 
less precise and paternal education instead appeared somewhat more important, suggesting that role model effects might be at play. If cognitive and non-cognitive skills are important mechanisms behind the transmission of education, our results can thus provide some clues to what is going on, as father's education mattered more for the development of these skills. Even though our results suggest that mother's education matters more for the development of health, this is perhaps a less important mechanism in a country such as Sweden, with universal health insurance coverage. In fact, this is what the findings in a recent paper by Lundborg et al. (2016) suggest, where the effect of early-life health on educational attainment was estimated in a sample of MZ twins. When accounting for genetics and early-life environment, the effects of various early-life health measures on later educational attainment were small and insignificant. Note, however, that Amin et al. (2015) found a significant effect of mother's education on their daughter's education that was larger than the effect of paternal education. Since we do not have females in the military enlistment register, we cannot test if mother's education affects daughter's skills to a larger extent than son's skills or if there is an effect of early life health on educational attainment among females.

In sum, the results obtained using the twin sample and the adoptee sample suggest that cognitive skills, non-cognitive skills, and health may be important mechanisms through which the intergenerational transmission of schooling arises. A picture that emerges is that paternal education seems to matter more for the development of their sons' skills, whereas the mother's education matters more for the development of their health.

\subsection{Comparing the twin and adoption results}

Although the results came out as rather similar across research designs, there were also a few differences. While maternal education did affect the child's cognitive skills in both design, the effect became small and insignificant in the sample of adoptees when accounting for assortative mating. The effect of parental education on children's cognitive skills was also smaller in magnitude in the sample of adoptees than in the sample of sons of twins. The estimates were strikingly similar in magnitude, however, when we restricted the analyses on adopted children to those adopted within the first year of life.

Next, we examine if the small remaining differences reflect that adoptive parents, for some reason, are more or less efficient in transmitting skills, or prefer to transmit less or more skills, to their adopted children compared to biological parents. This will also shed light on the external validity of the adoption-based estimates.

In order to investigate whether adoptive parents are more or less nurturing than other parents, we can compare the effect of education on own-birth sons with an adopted sibling with the effect on own-birth sons without an adopted sibling (see, e.g. Plug 2004; Holmlund et al. 2011). ${ }^{30}$ If adoptive parents are more nurturing, we

\footnotetext{
${ }^{30}$ These regressions do not control for spouse's education.
} 
would expect a greater effect for the group of own-birth children with an adopted sibling. As shown in panel A of Table 7, the association between parental education on their biological child's cognitive skills, non-cognitive skills, health, and height is in all cases equal or less in magnitude if the child has an adopted sibling compared to the estimates for biological children shown in Table 3. Thus, we obtain no evidence that adoptive parents are more nurturing, as is often assumed, but, if anything, rather the opposite.

We next test for evidence that adoptive parents treat adopted children differently from own-birth children by comparing the effect of parental education for adopted sons who have an own-birth sibling to the corresponding effect for adopted sons without an own-birth sibling (Holmlund et al. 2011). In the former case, the adoptee competes for parental attention with the biological child. If the latter effect is greater, this would support the idea that parents treat adopted children worse. Since the sample size shrinks substantially when we single out adoptees with biological siblings, however, the estimates are imprecise, as shown in the lower panel of Table 7. There is a tendency towards smaller point estimates for most of the outcomes, but since all estimates are imprecisely measured, we refrain from any definitive statements in this case. What we can say is that the results do not provide any strong evidence that adoptive parents treat their adoptees better or worse than their biological children.

\subsection{Comparing the results to IV-based evidence}

In Lundborg et al. (2014b), instrumental variables estimates of the effect of education on child outcomes was presented. Since the data sources used, and the outcomes

Table 7 External validity of adoptee estimates

\begin{tabular}{lllll}
\hline & Cognitive & Non-cognitive & Health & Height \\
\hline Panel A: effect of parental education for own-birth sons with an adopted male sibling & \\
Paternal education & 0.087 & 0.013 & 0.005 & 0.014 \\
& $(0.008)^{* * *}$ & $(0.009)$ & $(0.009)$ & $(0.008)^{*}$ \\
Maternal education & 0.097 & 0.019 & 0.010 & 0.009 \\
& $(0.009)^{* * *}$ & $(0.010)^{*}$ & $(0.010)$ & $(0.008)$ \\
$N$ & 1448 & 1391 & 1361 & 1453 \\
Panel B: effect of parental education for adopted sons with a biological male sibling & 0.000 & 0.019 \\
Paternal education & 0.016 & 0.022 & $(0.013)$ & $(0.012)$ \\
& $(0.012)$ & $(0.013)^{*}$ & 0.009 & -0.005 \\
Maternal education & 0.017 & 0.012 & $(0.014)$ & $(0.013)$ \\
& $(0.013)$ & $(0.015)$ & 788 & 807 \\
\hline
\end{tabular}

Each coefficient represenets a separate regression. In all columns, age at adoption and country of birth fixed effects are included in the model. Standard errors are shown below the coefficients. ${ }^{* * *} p<0.01$, $* * p<0.05, * p<0.1$ 
studied, were the same as in this paper, a comparison of the results is informative (as we know that the differences in results are not driven by differences in the data). Instead, differences could capture differences in the assumptions invoked in the difference methods and/or differences in the variation in the data used to identify the effects.

The IV estimates in Lundborg et al. (2014b) show that only mothers' schooling matters and that it has a positive impact on sons' cognitive and non-cognitive skills. This contrasts with the results in this paper, where mothers' schooling matters only for cognitive skills and where fathers' schooling matters for cognitive and non-cognitive skills, in both the twin and adoption design. The differences in results may reflect differences in the sources of variation used in the designs. As shown in Lundborg et al. (2014b), the IV estimates are based on variation at the lower end of the schooling distribution, induced by the Swedish schooling reform which increased the mandatory years of primary schooling from 7 to 9 . This particular variation in schooling is not used in the adoption and twin design, since the cohorts we study were not affected by the schooling reform. These designs therefore excludes exactly the sources of variation in the data used in the IV design and if the returns to schooling varies across the schooling distribution, this may explain the differences in results. In fact, Lundborg et al. (2014b) show that there are no income returns to schooling for fathers in the IV design whereas there are positive returns in the twin design, using the same twin data as in this paper. So, the twin and adoption design uses variation in schooling across the entire schooling distribution whereas the IV design uses variation at the lower end.

Yet another difference across the designs is that the IV design only captures the effect among the compliers of the schooling reform, who may face different returns to schooling than other subgroups of the population studied. The difference in results for fathers may thus reflect that fathers who were forced to stay 9 instead of 7 years in school face smaller returns to schooling than other fathers and/or that that returns to fathers' schooling is smaller at the lower end of the education distribution.

The results for health in this paper are more in line with the IV results. The magnitudes of the IV estimates are greater in magnitude, however, suggesting that the effect of maternal schooling might be larger at the lower end of the parental education distribution.

Summing up, the comparison suggests that maternal schooling may be more important in low-educated families, whereas fathers' schooling is more important in somewhat higher educated families, where it mainly influences skills formation and to a lesser degree health.

Besides the reasons discussed above, the methods may also give different results because the identifying assumptions differ. The IV design critically rests on the assumption of exogeneity of exposure to the schooling reform and on the validity of the exclusion restriction. The twin design needs to assume that schooling differences across twin parents are more or less randomly generated. In the adoption design, we instead need to assume random placement of adoptees and that adoptee parents' 
schooling is unrelated to parents' unobserved child-rearing endowments or that these endowments do not affect their adopted children's outcomes. These are all identifying assumptions that cannot be proven and any differences in results across the methods could reflect differences in identifying assumptions.

\subsection{Are earlier grades and tracking affecting child skills and health at 18 ?}

Our results so far are consistent with the idea that parental education matters for children's education partly because parental education improves children's skills and health. One could not rule out the possibility, however, that children's skills and health, as measured at age 18, are affected by earlier study results or choice of track in school, so that parental education affects children's skills and health by improving their study outcomes. Note, however, that this would still imply a causal effect of parental education on children's skills and health, only that part of it run through early life educational attainment. We analysed this by analysing the link between parental education and children's final grades in math and Swedish from compulsory school (at age 16). This information is only available for the cohorts born 1972 to 1979. ${ }^{31}$ The results showed small and insignificant effects of parental education on grades in both the sample of adoptees and cousins (results available on request). ${ }^{32}$ So, even if there is an effect of earlier educational attainment on skills and health, these results provide no evidence that the effect of parental education on children's skills and health runs through earlier educational attainment of the children. It should be noted, however, that since the sample size is smaller when using grades as an outcome, power might be too low to detect a significant effect. Our results are similar to those of Hægeland et al. (2010), who found no effect of twin parent's education on their children's grades and tiny effects of adoptive mother's education. ${ }^{33}$

\subsection{How large are the effects and how do they relate to previous findings?}

Our twin- and adoption-based estimates may appear rather small, but so are the recent estimates on the effect of parental education on children's education in the literature. But are the magnitudes of our estimates reasonable, given the previous estimates on the intergenerational transmission of human capital? We can shed some light on this, by examining to what extent our estimates, together with previous estimates on the schooling returns to skills, could generate the observed transmission of schooling.

\footnotetext{
${ }^{31}$ The sample sizes therefore shrinked to 2,748 adoptees and 222 and 190 children of twin mothers and twin fathers, respectively.

${ }^{32}$ When we examine the effect of parental education on skills for the same subsample born 1972-1979 our main results do not change, i.e. we still obtain a positive effect of parental education on skills. These results are available on request.

${ }^{33}$ The effect was such that 1 year of additional schooling increased exam marks by $2 \%$ of a standard deviation and the estimated coefficient was only significant at the $10 \%$ level.
} 
Taking cognitive skills as our example, and starting with twins, our twin-based estimates for paternal and maternal schooling converge around 0.05 in most specifications. This means that one additional year of paternal schooling is associated with a $5 \%$ of a standard deviation increase in the child's cognitive skills. Sandewall et al. (2014) and Lundborg et al. (2016) provide twin-based estimates of the schooling returns to cognitive skills, where in both studies a one standard deviation increase in cognitive skills is associated with about 0.5 additional years of schooling. Note that both these studies are based on the Swedish enlistment data. Assuming that these estimates are also valid for our population of twins they imply that a 5\% of a standard deviation increase in cognitive skills, which resulted from 1 additional year of parental schooling, is associated with 0.025 additional years of schooling by the child. Since Amin et al. (2015) reported that 1 additional year of paternal schooling is associated with $0.04-0.06$ additional years of schooling by the child, depending on whether spouse's education is controlled for or not, our estimate for cognitive skills would thus alone be able to explain about half of the causal transmission of schooling across fathers and sons. This is reassuring and makes our twin-based estimates appear very reasonable.

Are our results for adoptees also reasonable? We are not aware of any previous adoptee-based estimates of the schooling returns to skills or health. With our data, we can, however, provide cross-sectional estimates of the schooling returns to skills for adoptees. We can also use a smaller sample of sibling adoptees and examine to what extent the estimates change when imposing family fixed effects. Our cross-sectional estimates suggest that a one standard deviation increase in cognitive skills is associated with 0.77 additional years of schooling (not shown but available on request). When we impose adoptee-sibling fixed effects, for the sample with several adoptees in the same family, the point estimate declines somewhat to 0.73 . This is most likely still an overestimate, as the adoptee-siblings differ in genetics and early childhood conditions, i.e. before entering Sweden. Note that the cross-sectional estimates of the schooling returns to cognitive skills in Lundborg et al. (2016) were roughly halved in magnitude when imposing twin pair fixed effects. If this decrease is indicative of what would have happened also among our adoptees, an estimate of about 0.4 would be indicated. This, again, means that our adoptee-based estimates on the effect of parental education on cognitive skills of 0.014 to 0.027 could explain a substantial part of the transmission of education from adoptive parents to their adopted sons.

\section{Summary and conclusions}

Recent literature has established that the intergenerational transmission of education partly reflects a causal effect of parental education. In this paper, we provide some clues regarding what it is that well-educated parents bring to their children, so that their children obtain more education. We focused on youth skills and health that could plausibly be important mechanisms for the intergenerational transmission 
of education and employed the most common methods used in the literature: the adoption and the twin design.

Our results suggest that cognitive and non-cognitive skills, as well as health, may be important factors in understanding the intergenerational transmission of human capital. In both the adoption and the twin design, parental schooling had a positive impact on at least some of these child outcomes and the estimates were many times similar across the twin and adoption designs. Our results also suggest that paternal education was of greater importance for the development of the child's cognitive and non-cognitive skills, whereas the mother's education matters more for the child's health. Since we are only studying the outcomes of male children, one interpretation of these differences is that role model effects make fathers more important for the development of skills whereas mothers matter more for health investments in children. Moreover, since it is well established that skills and health affect educational attainment, our results thus suggest that part of the effect of parental schooling on children's schooling reflects an effect of parental schooling on children's skills and health.

We believe that our estimates appear very reasonable, given the previous estimates using an adoption and a twin design that estimate the intergenerational transmission of schooling in Scandinavian countries. Using our estimates of the effect of paternal schooling on cognitive skills as an example, and in addition using previous findings on the schooling returns to cognitive skills, we showed that our estimates appear reasonable.

Returning to some of the policy issues discussed in the introduction, our results suggest that interventions that increase the level of schooling in society may have benefits that not only span generations but also across a range of child outcomes. This is a useful finding since the level of education in society is something that can be manipulated by policy makers. For many reasons, it also appears more desirable that the transmission of human capital occurs mainly through children's skills and health, rather than through other less desirable mechanisms. A fruitful path for future research will be to continue to try to understand the mechanisms behind the intergenerational transmission of human capital.

Acknowledgments The authors would like to thank the anonymous referees for helpful comments and suggestions.

The authors thank Anders Björklund, Paul Devereux, Peter Fredriksson, Lars Kirkebøen, Mårten Palme, Erik Plug, Marte Rønning, Jonas Vlachos, and seminar participants at the UCD Dublin, Lund University, Stockholm University, Statistics Norway, and the EALE 2011 conference for useful comments and suggestions. A research grant from the Centre for Economic Demography (CED) at Lund University is gratefully acknowledged.

\section{Compliance with ethical standards}

Conflict of interest The authors declare that they have no conflict of interest.

Open Access This article is distributed under the terms of the Creative Commons Attribution 4.0 International License (http://creativecommons.org/licenses/by/4.0/), which permits unrestricted use, distribution, and reproduction in any medium, provided you give appropriate credit to the original author(s) and the source, provide a link to the Creative Commons license, and indicate if changes were made. 


\section{Appendix}

Table 8 Estimates of the relationship between parental education level and sons' outcomes: effects of the sum of parental education

\begin{tabular}{|c|c|c|c|c|}
\hline & Cognitive & Non-cognitive & Health & Height \\
\hline & \multicolumn{4}{|c|}{ Panel A: adopted sons } \\
\hline Sum of parents' & 0.014 & 0.007 & 0.007 & 0.035 \\
\hline education & $(0.003)^{* * *}$ & $(0.004)^{*}$ & $(0.004)^{*}$ & $(0.022)$ \\
\hline \multirow[t]{2}{*}{$N$} & 3692 & 3375 & 3631 & 3741 \\
\hline & \multicolumn{4}{|c|}{ Panel B: sons of MZ twins } \\
\hline Sum of parents' & 0.048 & 0.041 & 0.026 & 0.017 \\
\hline education (twin mother) & $(0.011)^{* * *}$ & $(0.012)^{* * *}$ & $(0.012)^{* *}$ & $(0.010)^{*}$ \\
\hline$N$ & 1362 & 1266 & 1409 & 1348 \\
\hline Sum of parents' & 0.043 & 0.041 & -0.003 & 0.060 \\
\hline education (twin father) & $(0.012)^{* * *}$ & $(0.012)^{* * *}$ & $(0.013)$ & $(0.012)$ \\
\hline$N$ & 1132 & 1053 & 1189 & 1117 \\
\hline
\end{tabular}

Each coefficient represents a separate regression. In panel A, age at adoption and country of birth fixed effects are included in the model. In Panel B, twin pair fixed effects are included. Standard errors are shown below the coefficients. $* * * p<0.01, * * p<0.05, * p<0.1$

Table 9 Estimates of the relationship between parental education level and sons' health outcomes: specific diagnoses

\begin{tabular}{|c|c|c|c|c|c|c|}
\hline & \multicolumn{2}{|c|}{ Physical capacity } & \multicolumn{2}{|l|}{ Obesity } & \multicolumn{2}{|c|}{ Hypertension } \\
\hline & Adopted & $\begin{array}{l}\text { MZ twins } \\
\text { FE }\end{array}$ & Adopted & $\begin{array}{l}\text { MZ twins } \\
\text { FE }\end{array}$ & Adopted & $\begin{array}{l}\text { MZ twins } \\
\text { FE }\end{array}$ \\
\hline $\begin{array}{l}\text { Paternal } \\
\text { education }\end{array}$ & $\begin{array}{l}0.019 \\
(0.006)^{* * *}\end{array}$ & $\begin{array}{l}0.004 \\
(0.021)\end{array}$ & $\begin{array}{l}-0.002 \\
(0.001)^{*}\end{array}$ & $\begin{array}{l}-0.005 \\
(0.003)\end{array}$ & $\begin{array}{r}0.000 \\
(0.002)\end{array}$ & $\begin{array}{l}-0.011 \\
(0.009)\end{array}$ \\
\hline$N$ & 3253 & 1107 & 3741 & 1228 & 3741 & 1211 \\
\hline $\begin{array}{l}\text { Maternal } \\
\text { education }\end{array}$ & $\begin{array}{l}0.019 \\
(0.007)^{* * * *}\end{array}$ & $\begin{array}{l}0.023 \\
(0.018)\end{array}$ & $\begin{array}{l}-0.002 \\
(0.001)^{*}\end{array}$ & $\begin{array}{l}0.002 \\
(0.003)\end{array}$ & $\begin{array}{l}0.003 \\
(0.002)\end{array}$ & $\begin{array}{l}0.000 \\
(0.008)\end{array}$ \\
\hline$N$ & 3253 & 1687 & 3741 & 1913 & 3741 & 1862 \\
\hline
\end{tabular}

Each coefficient represents a separate regression. The dependent variables are the son's physical capacity, obesity, and hypertension status. For adopted children, age at adoption and country of birth fixed effects are included in the model. Standard errors are shown below the coefficients. $* * * p<0.01$, $* * p<0.05$, $* p<0.1$ 


\section{References}

Almond D, Currie J (2011) Human capital development before age five. In: Ashenfelter O, Card D (eds) Handbook of labor economics, chap 15. Elsevier, pp 1315-1486

Amin V, Lundborg P, Rooth D (2011) Following in your father's footsteps: a note on the intergenerational transmission of income between twin fathers and their sons. IZA Discussion Paper No. 5990

Amin V, Lundborg P, Rooth D (2015) The intergenerational transmission of schooling: are mothers really less important than fathers? Econ Educ Rev 47:100-117

Anger S, Heineck G (2010) Do smart parents raise smart children? The intergenerational transmission of cognitive abilities. J Popul Econ 23:1105-1132

Ashenfelter O, Krueger AB (1994) Estimates of the returns to schooling from a new sample of twins. Am Econ Rev 84:1157-1173

Becker G, Tomes N (1976) Child endowments and the quantity and quality of children. J Polit Econ 84:143-162

Behrman JR, Rosenzweig MR (2002) Does increasing women's schooling raise the schooling of the next generation? Am Econ Rev 92:323-334

Behrman JR, Rosenzweig MR (2004) Returns to birthweight. Rev Econ Stat 86:586-601

Behrman JR, Pollak RA, Taubman P (1982) Parental preferences and provision for progeny. J Polit Econ 90:52-73

Berg vanden, Lundborg GP, Nystedt P, Rooth D (2014) Critical periods during childhood and adolescence: a study of adult height among immigrant siblings. J Eur Econ Assoc 12(6):1521-1557

Bingley P, Christensen K, Myrup Jensen V (2009) Parental schooling and child development: learning from twin parents. SFI working paper No. 07-2009

Björklund A, Lindahl M, Plug E (2006) The origins of intergenerational associations: lessons from Swedish adoption data. Q J Econ 121:999-1028

Björklund A, Salvanes K et al (2010a) Education and family background: mechanisms and policies. In: Hanushek EA (ed) Handbook in economics of education, vol. 3. North Holland, Amsterdam

Björklund A, Hederos Eriksson K, Jäntti M (2010b) IQ and family background: are associations strong or weak? B.E J Econ Anal Policy (Contributions) 10:1-12

Black S, Devereux P (2010) Recent developments in intergenerational mobility, forthcoming. In: Ashenfelter O, Card D (eds) Handbook of labor economics. Elsevier, Amsterdam

Black S, Devereux P, Salvanes K (2005) Why the apple doesn't fall far: understanding intergenerational transmission of human capital. Am Econ Rev 95:437-449

Black S, Devereux P, Salvanes K (2007) From the cradle to the labor market? The effect of birth weight on adult outcomes. Q J Econ 122(1):409-439

Black S, Devereux P, Salvanes K (2009) Like father, like son? A note on the intergenerational transmission of IQ scores. Econ Lett 105:138-140

Bound J, Solon G (1999) Double trouble: on the value of twins-based estimation of the return to schooling. Econ Educ Rev 18:169-192

Bozzoli C, Deaton A, Quintana-Domeque C (2009) Adult height and childhood disease. Demography 46(4):647-69

Carneiro P, Meghir C, Parey M (2013) Maternal education, home environments and the development of children and adolescents. J Eur Econ Assoc 11(1):123-160

Cesarini D, Johannesson M, Oskarsson S (2014) Pre-birth factors, post-birth factors, and voting: evidence from Swedish adoption data. Am Polit Sci Rev 108(1):71-87

Chevalier A (2004) Parental education and child's education: a natural experiment. IZA discussion paper No. 1153

Chevalier A, O'Sullivan V (2007) Mother's education and birth weight. Geary Institute Working Paper 200725

Corak M, Piraino P (2011) The intergenerational transmission of employers. J Labor Econ 29:37-68

Currie J (2009) Healthy, wealthy, and wise: socioeconomic status, poor health in childhood, and human capital development. J Econ Lit 47:87-122

Currie J, Moretti E (2003) Mother's education and the intergenerational transmission of human capital. Evidence from college openings. Q J Econ 118(4):1495-1532

Dearden LS, Machin S, Reed H (1997) Intergenerational mobility in Britain. Econ J 110:47-64

De Haan M (2011) The effect of parents' schooling on child's schooling; a non-parametric bounds analysis. J Labor Econ 29:859-892 
Elo IT, Preston SH (1992) Effects of early-life conditions on adult mortality: a review. Popul Index 58:186-212

Griliches Z (1979) Sibling models and data in economics: beginnings of a survey. J Polit Econ 87:37-64

Grönqvist E, Öckert B, Vlachos J (2016) The intergenerational transmission of cognitive and non-cognitive abilities, forthcoming. J Hum Resour

Haveman RH, Wolfe BL (1995) The determinants of children's attainments: a review of methods and findings. J Econ Lit 33:1829-1878

Hægeland T, Kirkeben L, Raaum O, Salvanes K (2010) Why children of college graduates outperform their schoolmates: a study of cousins and adoptees. IZA DP 5369

Heckman J, Stixrud J, Urzua S (2006) The effects of cognitive and noncognitive abilities on labor market outcomes and social behavior. J Labor Econ 24:411-482

Hjalmarsson R, Lindqvist M, Holmlund H (2015) The effect of education on criminal convictions and incarceration: causal evidence from micro-data. Econ J 125(587):1290-1326

Holmlund H, Lindahl M, Plug E (2008) The causal effect of parent's schooling on children's schooling: a comparison of estimation methods/ IZA Discusson Paper No. 3630

Holmlund H, Lindahl M, Plug E (2011) The causal effect of parents' schooling on children's schooling: a comparison of estimation methods. J Econ Lit 49:615-51

Isacsson G (1999) Estimates of the return to schooling in Sweden from a large sample of twins. Labour Econ 6:471-489

Knudsen E, Heckman J, Cameron J, Shonhof JP (2006) Economic, neurobiological, and behavioural perspectives on building America's future workforce. Proc Natl Acad Sci 103(27):10155-10162

Lindahl M, Lundborg E, Palme P, Simeonova E (2016) Parental influences on health and longevity: lessons from a large sample of adoptees. NBER Working Paper No. 21946

Lindeboom M, van der Klaauw B, Nozal A (2009) Parental education and child health: evidence from a schooling reform. J Health Econ 28:109-131

Lindqvist M, Hjalmarsson R (2010) Driving under the influence of our fathers. B.E J Econ Anal Policy 10:1-15

Lindqvist M, Hjalmarsson R (2012) Like godfather, like son: explaining the intergenerational nature of crime. J Hum Resour 47(2):550-582

Lindqvist M, Hjalmarsson R (2013) The origins of intergenerational associations in crime: lessons from Swedish adoption data. Labour Econ 20(1):68-81

Lindqvist E, Vestman R (2011) The labor market returns to cognitive and noncognitive ability: evidence from the Swedish enlistment. Am Econ J: Appl Econ 3:101-128

Lundborg P, Nystedt P, Olof Rooth D (2014a) Height and earnings: the role of cognitive and non-cognitive skills. J Hum Resour 49:141-166

Lundborg P, Nilsson A, Rooth D (2014b) Parental education and offspring outcomes: evidence from the Swedish compulsory schooling reform. Am Econ J: Appl 6(1):253-278

Lundborg P, Nilsson A, Rooth D (2016) Does health predict schooling differences within monozygotic twin pairs? J Popul Econ 29:1191-1215

Miller P, Mulvey C, Martin N (2005) Birth weight and schooling and earnings: estimates from a sample of twins. Econ Lett 86:387-392

Maurin Eric, McNally Sandra (2008) Vive la révolution! long term returns of 1968 to the angry students. J Labour Econ 26(1):1-33

McCrary J, Royer H (2011) The effect of female education on fertility and infant health: evidence from school entry policies using exact date of birth. Am Econ Rev 101(1):158-95

Oreopoulos P, Page M, Stevens AH (2006) The intergenerational effects of compulsory schooling. J Labor Econ 24(4):729-760

Piopiunik M (2014) Intergenerational transmission of education and mediating channels: evidence from a compulsory schooling reform in Germany. Scand J Econ 116:878-907

Plug E (2004) Estimating the effect of mother's schooling on children's schooling using a sample of adoptees. Am Econ Rev 94:358-368

Plug E, Vijverberg W (2003) Schooling, family background, and adoption: is it nature or is it nurture? J Polit Econ 111:611-641

Pronzato C (2010) An examination of paternal and maternal intergenerational transmission of schooling, forthcoming. J Popul Econ 25:591-608

Rosenzweig MR, Schultz TP (1982) Market opportunities, genetic endowments, and intrafamily resource distribution: child survival in rural India. Am Econ Rev 72:803-15 
Royer H (2009) Separated at girth: US twin estimates of the effects of birth weight. Am Econ J: Appl Econ 1:49-85

Rutter M, Andersen-Wood L, Beckett C et al (1998) Developmental catch-up, and deficit, following adoption after severe global early privation. J Child Psychol Psychiatr 39:465-476

Sacerdote B (2000) The nature and nurture of economic outcomes. NBER Working Paper No. 7949

Sacerdote B (2002) The nature and nurture of economic outcomes. Am Econ Rev Pap Proc 92:344-348

Sacerdote B (2007) How large are the effects from changes in family environment? A study of Korean American adoptees. Q J Econ 122:119-157

Sacerdote B (2011) Nature and nurture effects on children's outcomes: what have we learned from studies of twins and adoptees? In: Benhabib J, Bisin A, Jackson MO (eds) Handbook of social economics, chapter 1. Elsivier, Amsterdam

Sandewall Ö, Cesarini D, Johannesson M (2014) The co-twin methodology and returns to schooling. testing a critical assumption. Labour Econ 26(1):1-10

SOU (2003) Swedish Official Government Report. Adoptionsutredningens Bet änkande Adoption-Till Vilket Pris? (Stockholm)

Thompson O (2014) Genetic mechanisms in the intergenerational transmission of health. J Health Econ 35:132-146 